\title{
DOWN THE RABBIT HOLE 11/22/63: STEPHEN KING'S HISTORICAL CHANGELING
}

\author{
BETTY LATHAM \\ Texas A\&M University Central Texas
}

\begin{abstract}
Once something becomes a story and it is appropriated in some way, that story experiences an additional, altered life. The adaptation might echo the original, but it does so in such a way that the original is forever changed. The original becomes a "changeling." On a personal level we view events that we have "witnessed" through the lens of our own experiences. This is even true when one revisits the past through fiction. The reader or spectator experiences the past through the lens of the adapter. Stephen King admitted to being emotionally invested in the events surrounding the assassination of President John Fitzgerald Kennedy in 1963, and this emotional investment is reflected in his adaptation. Stephen King's novel, 11-22-63, and its TV adaptation, serve as compelling examples of how emotional responses to the past can inform their adaptations, alter how their audiences explore and re-visit the past, and demonstrate how history and adaptations become changelings. King's adaptation additionally demonstrates his ability to integrate the Kennedy assassination back into popular culture, inviting and allowing a "new" younger audience (who were not alive at the time of the assassination) to "experience" history by accompanying his characters down the rabbit hole of history.
\end{abstract}

Keywords: adaptation, appropriation, film and history, emotional response, popular culture

Every September in America many people reflect about what they were doing on 9-11-2001. In other parts of the world individuals might have vivid recollections of their reactions to the fall of the Berlin Wall, the massacre in Tiananmen Square, the death of Princess Diana, or the toppling of Saddam Hussein's statue in Bagdad. The mention of significant historical events like these often provokes strong emotion. Such events become an emotional marker and impact the way that we, as individuals view the world. We don't see history like 9-11 as a series of facts; we see it through the lens of our own experiences and emotions of that day. We change history the moment it touches our lives.

Two of my earliest memories of notable historical events reflect the impact of John Fitzgerald Kennedy on the world. I was just six years old and 
clearly remember a disturbing feeling that enveloped Britain in 1962. I was staying with relatives in the north of England and recall hearing discussions about the possibility of World War Three. As a little girl, I was worried that I would never be able to return home to London. However the threat passed. It was not until many years later, possibly into adulthood, I realized that it was the Cuban Missile Crisis that caused the reverberating fear in Britain, and other parts of the world. A little over a year later, I was impacted by the assassination of President Kennedy. This time I remember the event because it affected popular culture. My family was watching the ITV soap opera Coronation Street! I recall that my parents became increasingly annoyed because news bulletins kept interrupting the program, and finally ITV cut away from regularly scheduled programming to focus on the events in Dallas, Texas. I was put to bed!

My husband's experience was totally different. He was fifteen years old living in Dallas, and recalls:

It was lunch-time and we were going to the lunch room. Kids were streaming out, yelling 'the President's been shot, the president's been shot.' The loudspeaker came on and a somber, emotionally charged voice said that President Kennedy was dead. When I went home and walked in the door, my Dad (55 years old) was sitting and watching television. He stood up crying. He cried like a baby (B. Latham)

The experiences that my husband and I had were quite different. I was a young English child, who, before the assassination, had not heard of John Fitzgerald Kennedy. My future husband was an American high school adolescent whose country's President was visiting the town where he lived. He and I were separated, not only by an ocean, but by different personal histories, different social structures, and different cultures. But for a moment we were united as humans living on the same small planet, sharing a collective experience with millions of others across the globe.

On a personal level, one's own experience of events, informs the way we view history. The event may be repeated as oral history or remembrances, or transcribed to paper in the form of historiography or historical fiction, and thereby becomes an adaptation. The adaptation might echo the original source, in this case the event itself, but it does so in such a way that the original is forever changed; it becomes a changeling.

A changeling is that which replaces the original. Changeling narratives, from all cultural milieus, often employed tales of fantastical creatures such as fairies or trolls who came in the night and abducted sleeping newborns from their beds, and substituted instead cantankerous or deformed babies. Sir Walter Scott relates the beginning of a changeling tale from the Scottish Isles, in 1833: 
A certain woman having put out her child to nurse in the country, found, when she came to take it home, that its form was so much altered that she scarce knew it; nevertheless, not knowing what time might do, took it home for her own...(although) she thought it changed, and none of her child (Scott).

This sounds like a plot straight out of the pages of a Stephen King novel! However, I'm suggesting an alternative way to consider the changeling concept. Once history is appropriated and becomes a story, that story experiences an additional, altered life; it is an adaptation. The original (history) becomes a "changeling." This is especially true when one revisits the past through fiction. Stephen King's novel, 11/22/63, and the TV adaptation, 11.22.63, recently released in the United States, serve as compelling examples of this occurrence as both explicitly explore the consequences of re-visioning and revisiting the past.

American author Stephen King shared his experience of first hearing about JFK's assassination,:

We didn't get the news [...,] in school. But when we got into the [vehicle] to go home, the driver, Mike, had the radio on for the first time in living memory. We heard that Kennedy had been killed. Mike, who was kind of silent, spoke up: "They'll catch the (expletive) who did that and somebody will kill him." And that's exactly what happened. (King)

King was 16 when Kennedy was shot and expressed his desire to write about the event as early as 1972, but comments "even nine years after the deed the wound was still too fresh" (King 1085). By the time he was 24, King "got the idea for a story about a time-traveler trying to save JFK" (Greene 2016). King was a young "high school English teacher living in a double wide trailer and couldn't find anyone" to take his writings seriously (Greene). However, because of the emotional impact of the JFK assassination and the ongoing debate about the perpetrator or perpetrators, Stephen King could not quite give up the idea of his own adaptation.

King's 11.22.63 is at its most basic level, a time travel story. It is a fantasy. King figuratively takes the baby (the documented event of JFK's murder) out of the cradle and substitutes instead an adaptation "about a lonely, divorced high school teacher...that comes across a time portal...in the closet of a diner, and spends five years plotting a way to stop President Kennedy's assassination" (Greene). Many may question whether King's adaptation can be regarded as historical at all. Robert Rosenstone posits that to be "considered historical rather than simply a costume drama that uses the past as an exotic setting for romance and adventure, a film must engage the issues, ideas, data, and arguments of that discourse" (510). King's text demonstrates that although he does use a bygone era as a setting for romance and time-travel adventure, he also fulfills Rosenstone's requirements for the historical nomenclature, by 
engaging two specific audiences- those who were alive and emotionally impacted by the assassination, and those for whom the events are merely history.

King uses two characters to represent the two audiences - Al Templeton (Chris Cooper), who accidentally discovers the time travel portal, or rabbit-hole to the past, represents those who remember the assassination and the subsequent events; and Jake Epping (James Franco), a young English teacher whose knowledge of the events is sketchy at best, represents a "new" audience. Al Templeton describes his memory of $22^{\text {nd }}$ November 1963:

I was never very much for that Camelot (stuff). I remember walking down the street. I was just a kid and we'd look at each other for a second, then we'd look away. Some people were crying. Some people just stopped in the middle of the sidewalk, cause we all knew something had been broken in all of us that could never get repaired. (11.22.63. Hulu)

Stephen King, through the voice of Al Templeton, echoes the thoughts of many after the assassination, thinking that the event and its consequences altered the course of history. Al continues:

Have you heard about the butterfly effect? Do you think that if JFK had lived Robert Kennedy would have run for President? If Bobby doesn't run, (he doesn't get shot). Save JFK, save his brother. And then there's Vietnam. Johnson was the one who escalated everything in 'Nam. If Kennedy had survived no way does that escalation continue. Those boys - would have lived ... You save Kennedy, you make the world a better place (11.22.63. Hulu)

Al's statement "you save Kennedy, you make the world a better place" is really Al's thesis statement - his guiding mantra. Al Templeton and conspiracy theorists alike believe that many of the issues that the US is facing today stem from a singular act - the killing of JFK, and that the world would be a better place had the assassination not occurred. Al would have felt right at home with modern skeptics who gathered with Oliver Stone, director of the 1991 historical adaptation $J F K, 50$ years after the death of President Kennedy. Labeled as "Kennedy Assassination Buffs" by Time Magazine's Jack Dickey, the group is skeptical of the Warren Commission's findings that "Lee Harvey Oswald was the gunman whose bullets...wounded Texas Governor John Conally and killed Kennedy." Dickey described the naysayers as

sorrowful, not angry. 'If only Kennedy had lived," begin so many of their idle thoughts. (JFK) never would have escalated the war in Vietnam; he never would have let nearly 60,000 American troops and countless civilians die in Southeast Asia. He would have defused Cold War tensions and shrunk the U.S. nuclear arsenal. He really would have scattered the CIA to the winds. His murder killed a dream of peace and prosperity. (Dickey) 
Al Templeton's experiences in Vietnam and his dissatisfaction with the current state of affairs in the US clearly affect his life and view of the world. Skeptics like Al Templeton, Oliver Stone, and other conspiracy theorists are trying to imagine the state of the world, in general and the US in particular, if the figurative baby in the cradle had never been abducted. Fortuitously, for Al, his accidental discovery of the rabbit-hole enables him to travel back to the years immediately preceding Kennedy's assassination and to implement a plan, which would reset history. Al is determined to discover the "true" story, and to find out whether there was a conspiracy, or whether Lee Harvey Oswald had acted alone. Once he was sure that Oswald was the lone gunman he would prevent the assassination. However, it is notable, at this point, that Al's repeated exposure to the rabbit hole and the past debilitates him, and he is forced to "pass the torch" (if you like) to the younger, Jake Epping.

This is an interesting move by King, because it actually mirrors what he is doing as a writer, and keeper and communicator of history. "Passing the torch" is also the move, on a smaller scale, that my husband and I, and others make as we retell our experiences of historical events that influenced us. King had admitted to being emotionally invested in the events of 11-22-63, and by finally writing the novel, and having it adapted to television, he is integrating the Kennedy assassination back into the forefront of popular culture, allowing a younger audience to become invested in the history.

When Al initially recruits Jake, he does not try to assail Jake with historical data and facts, but instead he shows Jake the past by encouraging him to go down the rabbit-hole himself. Kathryn Shultz in The New Yorker declares, "Of all the contributions that Lewis Carroll made to the English language burble, chortle, gimble, galumph - by far the most useful to contemporary culture is 'rabbit hole.' Carroll did not, of course, invent the rabbit hole; that distinction belongs to rabbits. But, with the publication of 'Alice's Adventures in Wonderland,' he did turn those holes into something that people could fall down - literally, in Alice's (or Al Templeton's or Jakes's) case or [...] figuratively for the rest of us." (Schultz) For Al and Jake the portal to the past is the rabbit hole; for contemporary audiences, unfamiliar with the JFK assassination, King's adaptation becomes the rabbit hole by which they can discover the past (or at least King's version of the past) for themselves.

Jake Epping, perhaps like many in contemporary society, is not emotionally invested in the past. He doubts that the events surrounding 11-22-63 had a significant impact on the world and only becomes engaged in the past because $\mathrm{Al}$ opens the rabbit-hole to him. But by going down the rabbit hole, Jake is able to connect with history by negotiating, not only basic issues such as dress and language, but more significant cultural issues such as class inequality and discrimination. As a result of his experiences down the rabbit hole, Jake is able 
to return with an acquired understanding of the past, which necessarily informs his relationship to the present. As a representation of new audiences, unfamiliar with the history, Jake (thanks to King) guides other readers or spectators down the rabbit-hole into the past.

Despite my own and my husband's personal ties and experiences in the sixties, our daughter, who's in her mid-twenties, didn't forge an emotional connection to that history until she went with Jake through Stephen King's rabbit-hole. She is an example of how King functions as an historian. I'll share her comments:

My understanding of the JFK assassination was limited. I had more knowledge of Jackie Kennedy and her mark on fashion than I did about JFK, his assassination, and the conspiracies surrounding his death. My knowledge could be summed up in three bullet points: a) JFK was assassinated; b) Probably Lee Harvey Oswald did it, but then again maybe not; and c) Everyone was really sad.

She continues,

I'm (representational of) the modern generation. This was my understanding of an important historical event. I couldn't even approximate the date Kennedy was assassinated. But by reading King's book, and then watching the miniseries, I will not only forever remember the date $11 / 22 / 63$, but I have developed a deeper understanding of the event. I understand now about the tumultuous conflict between the USSR and the United States. I understand Lee Harvey Oswald's ties to the conflict, and his extreme political beliefs. I grew sympathetic for his wife, Marina, when before reading the book I didn't even know her name. Finally, I forged a connection with the late 50's and 60's (and understand the conflicts and issues) in a way that I didn't before. I know and feel all of this, because of Stephen King. His adaptations led me toward a fascination with the JFK assassination, one I had never had before, and helped me develop viewpoints that would forever change how I consider JFK's death and the history behind his assassination. (Johnson)

Before being exposed to King's adaptation, first through his novel 11/22/63 and subsequently by watching the miniseries 11.22 .63 , my daughter would not have recognized either the figurative baby in the cradle or the changeling that King had created.

Jim Welsh, one of the founders of Literature Film Quarterly, asserts that "effective adaptations can both enlarge and amplify the "truth" of whatever is being adapted" (quoted in Raw, n.p.). This statement reinforces the idea that adaptation can itself be considered a changeling. A story, or in the case of $11 / 22 / 63$ - an historical event - is stolen, or borrowed from its source, and is essentially changed into an adaptation that gives it an additional, altered life 
which will always echo the original. Stephen King's adaptation, his rabbit hole, functions, not just as a portal - a door to the past or to an alternate reality - but also as a means by which audiences can engage or re-engage the issues, ideas, data, and arguments of the past. His rabbit hole, unlike Alice's original, “isn't a means to an end. It's an [...] end without end, inviting us ever onward, urging us to keep becoming, as Alice would say, curiouser and curiouser." (Shultz, n.p.) Stephen King, through Al and Jake, extends an invitation to a new audience and generation into the rabbit-hole of adaptation and information, allowing them to create their own historical changeling.

\section{Works Cited}

11.22.63. Dir. J .J. Abrams. Perf. James Franco. Sarah Gadon, George MacKay. Carpenter B/ Warner Bros. Television, 2010. Hulu.

Dickey, Jack . "Debunker among the Buffs." Time 182.22 (2013): 50. Academic Search Complete. Web. 1 Sep. 2016.

Greene, Andy. "How J. J. Abrams and Hulu Brought Stephen King's '11.22.63' to TV." Rolling Stone. 4 Feb. 2016.

Johnson, Jennie. Personal Interview, 1 Sep. 2016.

King, Stephen. 11/22/63. New York: Simon and Schuster, 2011. Print.

Latham, B. Personal Interview, 1 Sep., 2016.

Raw, Laurence. "Adaptation Past, Present and Future: An Interview with Jim Welsh." Journal of American Studies of Turkey, 33-34, 2011. 5-19. Print.

Rosenstone, Robert. "Historical Fact/ Historical Film." The American Historical Review, Vol. 97, 2 (Apr. 1992). 506-511. JSTOR. Web. 6 Sep. 2016.

Scott, Sir Walter, "On the Fairies of Popular Superstition." Introduction to "The Tale of Tamlane," Minstrelsy of the Scottish Border, Poetic Works 1833. Vol.2, 317321. Pitt.edu. Web. 30 Nov. 2015.

Shultz, Kathryn. "The Rabbit-Hole Rabbit Hole." The New Yorker. June 4, 2015. Google Scholar. Web. 30 Aug. 2016.

Toplin, Robert Brent. History by Hollywood: The Use and Abuse of the American Past. Urbana: U. of Illinois P/, 1996. Print.

Welsh, Jim. "'JFK': Why Were We in Vietnam?" Literature Film Quarterly, 20.3 (1992): 263-266. JSTOR. Web. 6 Sep, 2016. 